\title{
First delivery of a COVID-19 positive patient in Cameroon
}

\author{
Junie Y. Ngaha ${ }^{1}$, Florent Y. Fouelifack ${ }^{1,2 *}$, Madye A. Ngo Dingom ${ }^{1}$, Marileine K. Kemme ${ }^{1}$, \\ Brigitte Wandji $^{1}$, Felix Essiben ${ }^{3}$, Anicet Ngate $^{3}$, Jeanne H. Fouedjio ${ }^{1,2}$, Charles E. Sone ${ }^{1}$, \\ Philemon N. Arrey ${ }^{1}$, Serge Temkou ${ }^{1}$, Gilles T. Libend ${ }^{1}$, Jean J. Bissemou ${ }^{1}$, Filbert E. Eko ${ }^{1,2}$, \\ Joel T. Momo ${ }^{3}$, Larissa O. Essomba ${ }^{3}$, Ahmadou H. Djoulatou ${ }^{3}$, Ache Isseini, \\ Monkaree B. Kutnjem ${ }^{3}$, Colbert E. Bisong ${ }^{3}$, Winnie T. Gouanfo ${ }^{3}$, Rebecca Tonye ${ }^{1}$, \\ Georges E. Mballa ${ }^{1,3}$, Pierre Ongolo-Zogo ${ }^{1,3}$, Eugene Sobngwi ${ }^{1,3}$, \\ Pierre J. Fouda ${ }^{1,3}$, Robinson E. Mbu ${ }^{1,3}$
}

\begin{abstract}
${ }^{1}$ Department of Obstetrics and Gynecology, Yaounde Central Hospital, Yaounde, Cameroon
${ }^{2}$ Department of Obstetrics and Gynecology, Higher Institute of Medical Technology of Nkolondom, Cameroon

${ }^{3}$ Department of Medicine and Biomedical Sciences, University of Yaounde I, Cameroon
\end{abstract}

Received: 23 May 2020

Accepted: 30 June 2020

\section{*Correspondence: \\ Dr. Florent Y. Fouelifack, \\ E-mail: yfouelifack@gmail.com}

Copyright: (c) the author(s), publisher and licensee Medip Academy. This is an open-access article distributed under the terms of the Creative Commons Attribution Non-Commercial License, which permits unrestricted non-commercial use, distribution, and reproduction in any medium, provided the original work is properly cited.

\section{ABSTRACT}

Since its appearance in China in December 2019, COVID-19 which is caused by the SARS-CoV-2 virus has become a real global health problem. Pregnant women are not immune to this novel infection, which makes it difficult for proper management of pregnancy and childbirth. Authors present here the first case of childbirth in Cameroon of a 19-year-old adolescent tested positive for COVID-19.

Keywords: Cameroon, Central, Childbirth, COVID-19, Woman, Yaounde

\section{INTRODUCTION}

Coronaviruses $(\mathrm{CoV})$ form a large family of single stranded RNA viruses which generally infect different animal species. Some of them however may infect humans and manifest as a cold or benign flu-like illness. In December 2019, a novel coronavirus emerged (SARS-Cov-2) in China and spread rapidly across the globe. It has been identified as the causative agent of Coronavirus Disease 2019 (COVID-19) and is transmitted mainly by respiratory tract secretions and droplets from infected patients.

The clinical presentation is similar to the common cold: rapid onset fever, myalgia, fatigue, respiratory symptoms (dry cough or shortness of breath), and at times alterations in digestive symptoms as well. In about $20 \%$ of cases, the respiratory symptoms become very severe. ${ }^{2,3}$ The risk factors for severe disease include a pre-existing severe underlying disease, bacterial super-infection and direct pulmonary invasion by the virus. Advanced age (greater than 80 years) and tobacco consumption are aggravating factors. ${ }^{4}$ During the last months of pregnancy there is a relative immune depression so pregnant women are at risk of developing bacterial superinfections and severe forms, hence the necessity to screen at the slightest suspicions followed by a close monitoring of the maternal and foetal wellbeing. ${ }^{5}$ To date, there is no evidence of vertical transmission to the foetus and the disease is uncommon in the paediatric population. ${ }^{6,7}$ Given the novelty of the disease, several medical gaps are yet to be filled. Cases have to be described to permit the efficient elaboration of guidelines for management of COVID-19 positive pregnant women, their delivery and the post-partum period. It is in this light that we describe the first ever case of delivery in a COVID-19 positive patient at the Yaoundé Central Hospital, one of the treatment centres for COVID-19 positive patients in Cameroon. 


\section{CASE REPORT}

Ms YM, 19-year-old single, form 5 student, G1P0 at 35 weeks 6 days of gestation, living at the Nkolbisson neighbourhood on the outskirts of Yaoundé. She presented at the Yaoundé Central Maternity on the 2nd April 2020 complaining of dry cough associated with fever, headache and difficulty in breathing. The onset of symptoms dated to two weeks prior to consultation with dry cough, fever and generalised body pains for which she took $300 \mathrm{mg}$ of quinine sulphate tablets every 8 hours as well as paracetamol $1 \mathrm{~g}$ every 8 hours without improvement. Faced with the persistence of symptoms and the onset of dyspnoea, she came to consult in our hospital. Her pregnancy was not followed up and there was no prior documented antenatal contact. She however took Iron supplements but had never received any intermittent preventive treatment for malaria. She occasionally used a long lasting insecticide treated net. She had not had any previous hospitalisation during this index pregnancy and she had no chronic diseases. The patient had not been in contact with any persons from a different town or from any African or European country and she had not travelled recently. Being a student she had been in confinement in her home for the past two weeks since 18th March 2020, date at which schools had been officially closed in Cameroon. Her partner, a 26-year-old mechanic was her only identified contact. He had been carrying out his routine daily activities and was in apparent good health. On physical examination, we had an ill-looking patient who was febrile at 39.3 degrees Celsius. She had a respiratory rate of 30 cycles per minute, and oxygen saturation of $91 \%$ on ambient air. She presented neither nasal flaring nor intercostal recession and her cardiopulmonary auscultation was normal. On obstetrical examination, she had a gravid uterus with a symphysiofundal height of $29 \mathrm{~cm}$. The foetus was in cephalic presentation, foetal heart tones at 154beats /minute and no uterine contractions. Her cervix was posterior, long and closed. A presumptive diagnosis of lung disease in pregnancy at 35 weeks 6 days in a suspected Covid-19 positive patient was made given the current context. Oropharyngeal smears were collected using swabs immediately and sent to the Yaoundé Centre Pasteur laboratory (reference laboratory) for analysis by PCR technique. We received the results twenty-four hours later and was positive. An obstetrical ultrasound was carried out which showed a normally evolving singleton pregnancy of 31 weeks. The estimated foetal weight was $1700+/-275$ grams and there were no signs of foetal distress. A chest $\mathrm{x}$ ray was not done for fear of exposing the foetus to irradiation and neither was a CT scan done. She was then rapidly transferred to the Isolation Unit where she was managed as a case of COVID-19 disease in pregnancy. Her treatment comprised of azithromycin $500 \mathrm{mg} /$ day, amoxicillin-clavulanic acid $1 \mathrm{~g} / 8 \mathrm{~h}$, paracetamol $1 \mathrm{~g} / 8 \mathrm{~h}$ as well as respiratory assistance using a mobile oxygen extractor. Twenty-four hours after her admission in the Isolation Unit, staff from the maternity was called up to re-evaluate her because she had developed labour - type lumbo-pelvic pains. We set out to evaluate her after putting on appropriate protective material (jackets, protective over-coats, protective shoes, masks, caps, face shields, boots and sterile gloves). On examination we confirmed she was actually in labour having 3 uterine contractions in 10 minutes which lasted 30-
35 minutes. The foetal heart tones were normal and regular at 145 beats per minute. She was $7 \mathrm{~cm}$ dilated, cephalic engaged presentation, membranes were ruptured and liquor was yellowish. We concluded that she was in active phase of preterm labour. Given that delivery was imminent, it was no longer possible to transfer her to the delivery room and we decided with the team in the isolation unit to proceed with the delivery right in her bed. The neonatal unit was informed of the imminent delivery and appropriate measures were taken. The delivery material was brought in by a midwife on duty and we got ready to deliver the baby vaginally. One hour after our initial evaluation, the lady went into second stage of labour. The patient who had already been on facial mask oxygen was encouraged to bear down. The expulsive phase lasted 10 minutes and at 11:18 pm she was delivered of a female baby Apgar scores 8/10 and 10/10. The baby was separated from the mother and wrapped in prepared sterile drapes. Manual delivery of the placenta was done and it was confirmed complete. The bladder was emptied and the uterus was tonic. Uterine massage was initiated and then continued by the patient for thirty minutes. Vulvar toileting was done and the estimated blood loss was $100 \mathrm{ml}$. An intravenous line was setup with Ringers Lactate solution containing 20 international units of oxytocin to prevent uterine atony. The new born was transported by ambulance to the neonatal unit where she was received by a distinct neonatal unit team. The new-born was washed with warm water containing chlorhexidine solution. The birth weight was 2015 grams, height $46 \mathrm{~cm}$, head circumference $32 \mathrm{~cm}$. She was temporarily kept in an incubator and distant breast feeding began using breast milk which the mother who was still in the isolation unit pumped out using a breast pump. The next day, samples were collected from the baby for full blood count, blood group, C-reactive protein, blood electrolytes and for COVID-19 screening test. The woman on her part remained stable after delivery and presented no immediate post-partum complications. On day 2 postpartum, the patient had no complaints, her vital signs were normal with a respiratory rate of 18 cycles per minute and oxygen saturation of $98 \%$ using room air. Uterine involution was good and lochia was normal. From the obstetric point of view, she was ready to be discharged but this was delayed given that she had to continue her COVID-19 management in the isolation unit. The new born was thriving well. All the results of the tests done were within normal limits and her COVID-19 test was negative. Between day 2 and day 8 the new-born lost weight as is expected in all babies. On Day 10, she weighed $1947 \mathrm{~g}$. The mother and her baby were discharged on day 12 after a control COVID-19 test was negative in the mother.

\section{DISCUSSION}

This is reassuring news to pregnant women who have multiple fears for themselves and their babies in this era of the Covid-19 pandemic. Data published in the Lancet on March $7^{\text {th }}$ by a Chinese team were equally reassuring. ${ }^{8}$ Their retrospective study on nine patients in third trimester of pregnancy who were diagnosed with SARS Cov 2 and managed in a hospital in Wuhan between 20-31 ${ }^{\text {st }}$ January 2020 revealed that they had no particular vulnerabilities. None of the nine patients developed severe disease and none of them died. In this case the patient had mild symptoms and 
did not develop any complications before nor after delivery. The deliveries in the Wuhan series were done by caesarean section for medical reasons and in three of the patients they were premature babies. No effect of the Covid-19 was observed in the pregnancy but however spontaneous preterm onset of labour was noticed and could be linked to the fever and the cough. ${ }^{9}$ Prematurity was also identified in our case, spontaneous labour started in the 36th week of pregnancy. In France and in Quebec, the deliveries were centralized in maternities that had adequate protective gear to ensure the security of the personnel, Covid-19 positive women are not followed up in the same wards with Covid-19 negative women. ${ }^{10}$ Actually, before this experience, our service had not yet adapted a dedicated delivery room for Covid-19 positive patients. The delivery was therefore carried out in the Isolation Unit which had private sections using limited personnel. Authors did not authorize the presence of any family member given our limited capacity in support staff in charge of sterile dressing and disinfecting. Normal vaginal delivery is recommended by WHO unless there is another medical or obstetrical indication. The patients in the Wuhan series were all stable after delivery just like ours; morbidity in Covid-19 positive patients is not worse than in their nonpregnant counterparts. ${ }^{11,12} \mathrm{WHO}$ currently recommends that babies should not be separated from their mothers unless they present with moderate to severe disease or if the baby needs specialized care. ${ }^{11}$ The Kangourou mother care (KMC) method was not practiced in this case because given the limited personnel in the isolation unit, we were not certain that the young adolescent mother in her private ward will be able to meet up with the strict hygiene measures that go along with this method. Systematic screening of the baby was done in the Wuhan series though WHO does not recommend so. ${ }^{11}$ This case baby and the other babies in the Wuhan case series were all healthy. ${ }^{12}$ No vertical transmission of the disease has so far been described.

\section{CONCLUSION}

Standard procedures for delivery of Covid-19 positive women are the same for Covid-19 negative women, but delivery of Covid-19 positive patients should be carried out with adequate personal prevention equipment for the staff and the usage of a face mask by the parturient.

\section{ACKNOWLEDGMENTS}

Authors would like to thank patient for giving her consent to the publication of this case, as well as the administration of the central hospital of Yaoundé and its staff for their active implications in the care of this patient. Authors also thank the general director of PRODIPHARM for all the support he did for the neonatal care.

\section{Funding: No funding sources} Conflict of interest: None declared Ethical approval: Not required

\section{REFERENCES}

1. Zhong N, Zheng B, Li Y, Poon L, Xie Z, Chan K., and al. Epidemiology and cause of severe acute respiratory syndrome (SARS) in Guangdong People's Republic of China, in February, 2003 The Lancet. 2003;362:1353-8.

2. INSERM: Dossier sur les Coronavirus - Du simple rhyme au syndrome respirator ago severe. Available at: https://www.inserm.fr/information-en-sante/ dossiersinformation/coronavirus-sars-cov-et-mers-cov. Accessed $5^{\text {th }}$ May 2020.

3. OMS: Maladie à coronavirus 2019 (COVID-19): questions-réponses. Available at: https://www.who.int/fr/emergencies/diseases/novelcoronavirus-2019/advice-for-public/q-a-coronaviruses. Accessed $5^{\text {th }}$ May 2020.

4. Woo PCY, Lau SKP, Chu C, Chan K, Tsoi H, Huang $\mathrm{Y}$, et al. Characterization and complete genome sequence of a novel coronavirus corona virus HKU1, from patients with pneumonia. J Virol. 2005;79:884-95.

5. Peiris JSM, Guan Y, Yuen KY. Severe acute respiratory syndrome. Nat Med. 2004;10:S88-S97.

6. Zaki AM, van Boheemen S, Bestebroer TM, Osterhaus ADME, Fouchier RAM. Isolation of a Novel Coronavirus from a Man with Pneumonia in Saudi Arabia. N Engl J Med. 2012;367:1814-20.

7. Woo PCY, Lau SKP, Lam CSF, Lau CCY, Tsang AKL, Lau JHN, et al. Discovery of seven novel mammalian and avian coronaviruses in the genus delta corona virus supports bat coronaviruses as the gene source of alphacoronavirus and beta corona virus and avian coronaviruses as the gene source of gamma corona virus and delta corona virus. J Virol. 2012;86:39954008 .

8. Clinical features and obstetric and neonatal outcomes of pregnant patients with COVID-19 in Wuhan, China: a retrospective, single-centre, descriptive study. The Lancet Infectious Diseases. 2020.

9. Chen, Juanjuan Guo, Wang et al. Clinical characteristics and intrauterine vertical transmission potential of COVID-19 infection in nine pregnant women: a retrospective review of medical records. The Lancet. 2020;395(10226):809-15.

10. Couillard K. COVID-19: le point sur le suivi de grossesse et l'accouchement. Naître et grandir, 2020. Available at: https://naitreetgrandir.com/fr/nouvelles/ 2020/03/23/20200323-coronavirus-covid19-suivigrossesse-accouchement/. Accessed on $10^{\text {th }}$ June 2020

11. Q and A on COVID-19, pregnancy, childbirth and breastfeeding. Available at: www.who.int. Accessed on $23^{\text {rd }}$ March 2020.

12. Sara NI, Rachael O, Neggin M, Haleema S, Stacey G, Tamika A, et al. Covid-19 cases: an uncomplicated delivery in a patient with Covid-19 in the United States. N Engl J Med. 2020;382:e34.

Cite this article as: Ngaha JY, Fouelifack FY, Dingom MAN, Kemme MK, Wandji B, Essiben F, et al. First delivery of a COVID-19 positive patient in Cameroon. Int J Reprod Contracept Obstet Gynecol 2020;9:3477-9. 